\title{
REDESCRIÇÕES E NOTAS SOBRE DUAS ESPÉCIES DE CYRTONEURININAE (DIPTERA, MUSCIDAE)
}

\author{
Denise Pamplona ${ }^{1}$ \\ Márcia Souto Couri ${ }^{1,2}$
}

\begin{abstract}
REDESCRIPTIONS AND NOTES ON TWO SPECIES OF CYRTONEURININAE (DiPTERA, MusCIDAE). Redescription is made for Cyrtoneurina geminata (Stein, 1904), herein considered as a good species (not synonym of Cyrtoneurina gemina as stated in CARVALHo et al. 1993). The type-series of Paracyrtoneurina gluta (Giglio-Tos, 1893) (see PAMPLONA in press) is analysed and the male holotype and a female paratype are redescribed.

KEY WORDS. Diptera, Cyrtoneurininae, $C$. geminata, $P$. gemina, $P$. gluta, taxonomy
\end{abstract}

PAMPLONA (no prelo) fez uma revisão incluindo uma nova caracterização do gênero Cyrtoneurina Giglio-Tos, 1893 englobando nove espécies e descreveu Paracyrtoneurina com espécies anteriormente incluídas em Cyrtoneurina. Neste contexto, as espécies aqui abordadas são Cyrtoneurina geminata (Stein, 1904), Paracyrtoneurina gemina (Wiedemann,1830) e Paracyrtoneurina gluta GiglioTos, 1893.

C. geminata foi descrita originalmente em Spiloptera (STEIN 1904), com base em dois machos de La Pita (Guatemala ou Panamá ?). Na descrição original, STEIN (1904) mencionou a semelhança morfológica entre esta espécie e Paracyrtoneurina gemina, também descrita no mesmo trabalho. Destacou como principais diferenças a presença ou ausência de cílios nas asas: primeira veia longitudinal nua em C. geminata e, a terceira, com seis cerdas curtas apenas próximo à base.

SNYDER (1954) redescreveu C. geminata e citou que esta espécie era muito similar a C. uber Giglio-Tos, 1893. Comentou que as duas espécies ocorrem no Panamá, embora ambas tenham ampla distribuição na região neotropical. CARVALHO et al. (1993), no catálogo de muscídeos da região neotropical, propuseram a sinonímia das duas espécies. Ao examinar o material proveniente do "Museum für Naturkunde, Humboldt-Universität”, Berlin, Alemanha (síntipo macho) e do Museu Nacional, Universidade Federal do Rio de Janeiro (MNRJ) e comparando este material com os dados obtidos em SNYDER (1954), os presentes autores observaram diferenças morfológicas significativas entre estas duas espécies, que justificam tratá-las distintamente. Assim, C. geminata é redescrita e as diferenças morfológicas entre esta espécie e $P$. gemina são listadas numa tabela. Os caracteres do ovipositor

1) Departamento de Entomologia, Museu Nacional, Universidade Federal do Rio de Janeiro. Quinta da Boa Vista, São Cristóvão, 20940-040 Rio de Janeiro, Rio de Janeiro, Brasil.

2) Bolsista do CNPq. 
de C. geminata incluídos nesta tabela foram retirados de SNYDER (1954), que examinou mais de 650 e 190 especimens de $P$. gemina e C. geminata respectivamente.

\section{Cyrtoneurina geminata (Stein, 1904)}

Figs 1-5

Material-tipo. Síntipo macho[transcrição das etiquetas]: Brazilien/ Linchtwardt/ G. [etiqueta vermelha][manuscrito]; type [etiqueta vermelha]; geminata type Stein [manuscrito]; Zool. Mus. Berlin. (ZMHU). Em bom estado.

Diagnose. Fêmur II, na face ventral com uma cerda rombuda no terço basal; fêmur III, na face póstero-ventral com agrupamento de cerdas de ápice em gancho; tíbia III, na face ântero-ventral com quatro cerdas e face póstero-ventral com sete cerdas maiores na metade basal.

Coloração. Tórax castanho com polinosidade cinzenta e abdômen com áreas amarelo-translúcidas e manchas castanhas. Parafaciália, faciália e lúnula castanhas, com polinosidade prateada; gena castanha, com polinosidade cinza; pedicelo, flagelo e metade basal da arista amarelos; escapo com discreto tom castanho; probóscida e palpo castanhos. Mesonoto anteriormente à sutura, dois terços apicais do escutelo e pleura, com polinosidae mais intensa; úmero e ápice do escutelo amarelos. Asa sem manchas. Caliptras hialinas, a inferior com borda escurecida. Halter amarelo-claro. Espiráculo anterior amarelado; espiráculo posterior castanho, situado no centro de uma mancha castanho-escura, e com outra mancha acima dele. Pernas castanho-escuras.

Macho. Comprimento do corpo: $5,0 \mathrm{~mm}-5,5 \mathrm{~mm}$. Comprimento da asa: $5,0 \mathrm{~mm}$.

Cabeça: olhos nus, de bordas divergentes em direção ao vértice, afastados por um espaço cerca de 8,7 a 10 vezes menor que a largura da cabeça no nível do ocelo anterior; facetas ântero-internas maiores que as demais. Cerdas frontais em número de um par no nível da lúnula, seguido de cerca de cinco pares de cílios. Antena inserida abaixo do nível da metade do olho, com flagelo medindo cerca de 2,8 a 3,6 vezes o pedicelo. Arista plumosa em média com 14 cílios; cílios dorsais presentes. Vibrissa forte, cerca do comprimento da arista. Palpo em forma de bastão com cerca de 10 cílios longos na borda e outros fortes e curtos na face externa.

Tórax. Cerdas dorso-centrais 2:4; cerdas acrosticais $0: 1$; duas cerdas umerais, a externa um pouco maior que a interna; uma pós-umeral; uma pré-sutural; uma intra-alar; pré-alar ausente; duas supra-alares, a anterior maior; duas pós-supralares, a posterior o dobro da anterior; uma cerda intra pós-alar. Notopleura com cerdas semelhantes à pré-sutural. Escutelo com dois pares de cerdas basais, dois pares de laterais cerca da metade do par apical, um par de apicais; com muitos cílios na metade basal abaixo do nível das cerdas escutelares, na margem látero-ventral. Prosterno nu. Três cerdas proepisternais, a do meio maior; três cerdas pro-epimerais, a do meio maior. Propleura nua. Espiráculo anterior vertical e alongado. Anepisterno com cílios pequenos e uma série de sete cerdas na borda posterior. Catepisterno com pêlos de fundo longos e esparsos, 1:2 (a póstero-superior um pouco maior que a anterior porém menor que a pré-sutural). Anepímero ciliado. Catepímero nu. 


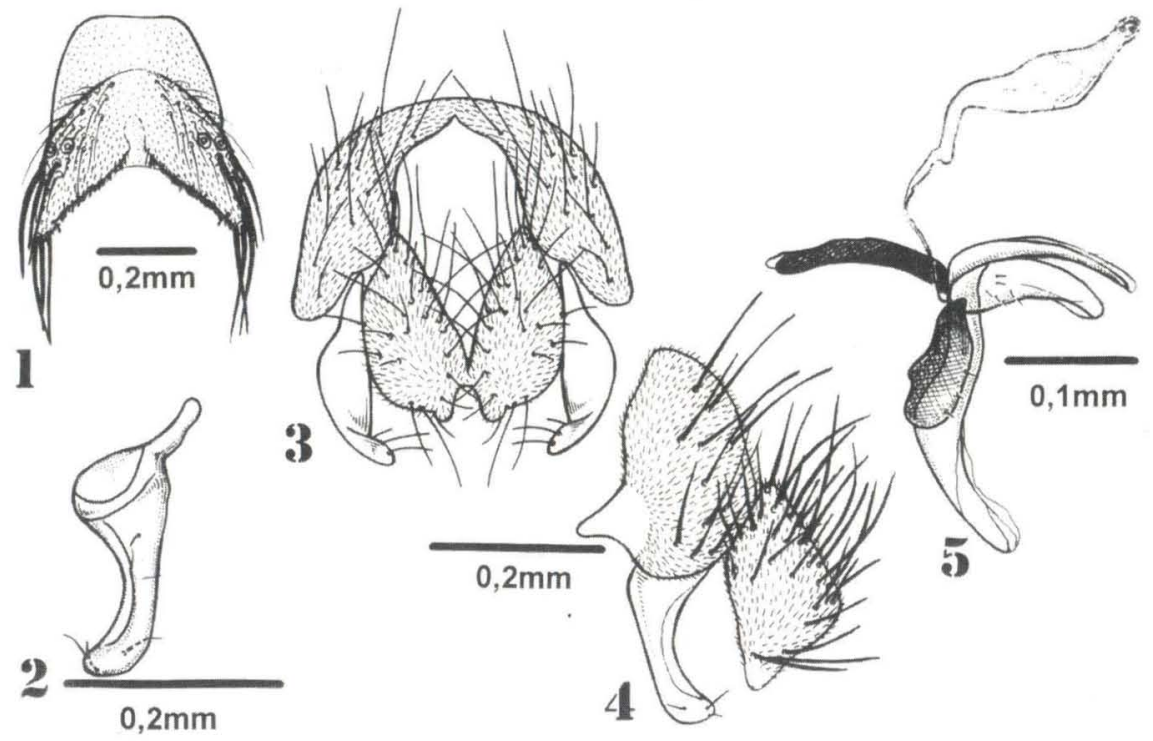

Figs 1-5. Cyrtoneurina geminata. (1) Quinto esternito, vista dorsal; (2) surstilo direito, vista dorsal; (3) epândrio, placa cercal e surstilo, vista dorsal; (4) epândrio, placa cercal e surstilo, vista lateral; (5) complexo fálico, vista lateral.

Espiráculo posterior, horizontal, alongado, um pouco mais largo que o anterior e com cílios negros ou castanhos na borda inferior. Caliptra inferior medindo cerca de 1,5 a 1,8 vezes a superior. Asa: $R_{1}$, faces dorsal e ventral, nuas; $R_{4+5}$, faces dorsal e ventral, ciliadas; $M_{1+2}$ próximo ao ápice com uma discreta curvatura na direção da $\mathrm{R}_{4+5}$; dm-cu reta ou no máximo ligeiramente sinuosa; remígio, na face dorsal, nu. Fêmur I, nas faces anterior e ântero-ventral sem cerdas; faces póstero-ventral e póstero-dorsal, com uma série de cerdas. Tíbia I, nas faces dorsal, póstero-dorsal e póstero-ventral, com uma cerda apical. Tarso com pêlos sensitivos longos, maiores na base do primeiro tarsômero. Fêmur II, na face ventral, com 1 cerda forte, curta e rombuda no terço basal, face ântero-ventral com uma série de cílios, mais curtos na metade apical; face posterior - póstero-dorsal com duas cerdas pré-apicais semelhantes entre si, fortes e inseridas obliquamente ao plano transversal do fêmur. Tíbia II, na face posterior com uma cerda no terço médio e uma sub-apical; faces anterior, ântero-ventral e ventral com uma, duas e duas cerdas apicais, respectivamente. Tarso sem pêlos diferenciados na base do primeiro tarsômero. Fêmur III, na face ântero-ventral com série de cerdas terminando em três cerdas maiores no terço apical; face póstero-ventral no terço apical, com agrupamento de cerdas longas de ápice em gancho. Tíbia III, na face ântero-ventral, no terço médio sem cerdas; face ântero-dorsal sem cerda pré-apical; face ventral com quatro cerdas no terço basal e face posterior com seis a sete cerdas no terço basal menores que as da face ventral. Quinto esternito com margem anterior reta; margem posterior com reentrância central e cerca de três cerdas no ápice lateral e cinco sub-apicais (Fig. 1). 
Terminália. Surstilo sem ciliação e com cerca de três cerdas no ápice e duas na metade basal (Fig. 2). Placa cercal com incisão posterior profunda (Figs 3-4). Parâmero e gonópodo aproximadamente do mesmo tamanho (Fig. 5).

Material examinado. Síntipo macho e um macho, BRASIL, Goiás: Campinas, XII-1935, Borgmeier e S. Lopes leg. (MNRJ); 1 macho, 2-I-1936 (MNRJ).

Registro geográfico. México, Guatemala, Honduras, El Salvador, Costa Rica, Panamá, Venezuela, Colômbia, Brasil, Peru e Paraguai.

Comentários. A tabela I auxilia na distinção de Cyrtoneurina geminata e Paracyrtoneurina gemina.

Paracyrtoneurina gluta foi decrita por GigLIO-Tos (1893), com base em um macho e uma fêmea.

SNYDER (1954: 459) designou como lectótipo, o espécimen macho desta espécie depositado na "Università de Torino", Torino, Itália, e verificou que o exemplar fêmea que o acompanhava, também de Tuxpango (Sumichrast), não pertencia ao mesmo táxon e sim a Cyrtoneurina rescita (Walker, 1861) (PAMPLONA no prelo), baseado principalmente, na descrição original da fêmea realizada por Giglio-Tos (1893), em que foi mencionada a presença de mancha na asa. Por outro lado, observou que uma outra fềmea pertencente à Coleção Bellardi, também depositada em Torino, com etiqueta "Cyrtoneurina gluta ? G.T." era co-específica com o lectótipo.

Com exame e dissecção de terminálias dos espécimens acima mencionados, a afirmação de SNYDER (1954) é aqui confirmada e são redescritos o lectótipo macho e a fềmea da Coleção Bellardi.

O material-tipo de $P$. gluta foi transferido do "Museo ed Istituto di Zoologia Sistematica della Università de Torino" (MIZSUT) para o "Museo Regionale di Scienze Naturali” (MRSN), Torino, Itália.

Tabela I. Caracteres distintivos entre Paracyrtoneurina gemina e Cyrtoneurina geminata.

\begin{tabular}{|c|c|c|}
\hline Caracteres & Paracyrtoneurina gemina & Cyrtoneurina geminata \\
\hline Número de cilios na arista & Cerca de 20 & Cerca de 14 \\
\hline Duas cerdas DC pós-suturais anteriores & Menores que a umeral interna & Maiores que a umeral interna \\
\hline Prosterno & Ciliado & $\mathrm{Nu}$ \\
\hline Aspecto da veia dm-cu & Sinuosa & Reta \\
\hline Ciliaçăo na face dorsal da R1 & Presente & Ausente \\
\hline Ciliação na face ventral da R1 & Presente & Ausente \\
\hline $\begin{array}{l}\text { Agrupamento de cerdas longas de ápice em gancho na } \\
\text { face póstero-ventral do fémur posterior no macho }\end{array}$ & & \\
\hline $\begin{array}{l}\text { face postero-ventral do femur posterıor no macho } \\
\text { Cerda no terço médio da face ântero-ventral da tíbia }\end{array}$ & Ausente & Presente \\
\hline posterior & Presente & Ausente \\
\hline Cerdas no terço basal da face ventral da tibia posterior & Ausente & Presente \\
\hline Ovipositor & Pouco telescopável, tubular & Não telescopável, nem tubular \\
\hline Cercos da fêmea & Largos, curtos e achatados & Estreitos, longos e cilindricos \\
\hline Tergitos VI e VII do ovipositor & Bem esclerotinizados & Pouco esclerotinizados \\
\hline Microtriquias nas membranas entre os segmentos VI-VII e & & \\
\hline VII-VIII, do ovipositor & Ausentes & Presentes \\
\hline Reentrância lateral do hipoprocto & Presente & Ausente \\
\hline $\begin{array}{l}\text { Reentráncia central na margem posterior do esternito } \mathrm{V} \\
\text { do macho }\end{array}$ & Ausente & Presente \\
\hline Cerdas no terço central do esternito $\vee$ do macho & Presente & Ausente \\
\hline $\begin{array}{l}\text { Reentrância central na margem posterior do quinto } \\
\text { esternito }\end{array}$ & Ausente & Presente \\
\hline Reentrância lateral da placa cercal do macho & Presente & Ausente \\
\hline
\end{tabular}




\section{Paracyrtoneurina gluta Giglio-Tos, 1893}

Figs $6-12$

Material-tipo. Lectótipo macho [transcrição das etiquetas]: [etiquetas manuscritas] 383[próximo algarismo ilegível]; Type of gluta/GT; [na outra face da etiqueta:] subsequent designation Snyder SL; Cyrtoneurina/ gluta/ Giglio-Tos. Material em estado regular de conservação, com asas rasgadas, sem perna II direita, com hifas de fungos.

Diagnose. Antena castanha; úmero castanho; cerdas dorso-centrais 2:3; com cinco cílios na metade basal látero-ventral do escutelo; tíbia I, na face posterior, com uma cerda no terço médio.

Coloração. Tórax castanho com polinosidade cinzenta e abdômen com áreas amarelo-foscas. Parafaciália, faciália e lúnula castanhas com polinosidade prateada; gena castanha com polinosidade cinza; antena castanha, com ápice do pedicelo castanho-claro. Probóscida e palpo castanhos. Mesonoto anteriormente à sutura, dois terços apicais do escutelo e pleura com polinosidade mais intensa; úmero e ápice do escutelo castanhos. Asa com mancha entre os ápices da Sc e da $\mathrm{R}_{1} \mathrm{e}$ uma discreta na $\mathrm{r}-\mathrm{m}$. Caliptra inferior com leve tom escurecido (sem borda escurecida na fêmea). Halter amarelo (mais claro na fềmea). Espiráculo anterior branco; espiráculo posterior castanho, e não situado no centro de mancha (pleura toda castanha). Pernas castanho-escuro.

Macho. Comprimento do corpo: 5,0 mm. Comprimento da asa: 5,5mm.

Cabeça. Olhos ciliados, de bordas paralelas em direção ao vértice, afastados por um espaço cerca de seis vezes menor que a largura da cabeça no nível do ocelo anterior; facetas ântero-internas maiores que as demais. Cerdas frontais em número de um par desenvolvido seguido de 5 ciliformes. Antena inserida no nível da metade do olho com flagelo medindo cerca de 2,9 vezes o pedicelo. Arista longamente ciliada com muitos cílios (impossível contar devido ao mau estado) e cílios dorsais secundários curtos que no terço basal da arista, medem cerca do diâmetro dela. Vibrissa forte, cerca do comprimento da arista. Palpo em forma de bastão, com muitos cílios na borda.

Tórax. Cerdas dorso-centrais 2:3; cerdas acrosticais $0: 1$; duas cerdas umerais, a externa cerca do dobro da interna; uma pós-umeral; uma cerda pré-sutural; uma intra-alar; cerda pré-alar ausente; duas supra-alares, a anterior maior; duas pós-supralares, a posterior o dobro da anterior; uma cerda intra-pós-alar. Notopleura com duas cerdas semelhantes e menores que a pré-sutural, com alguns cílios próximo à anterior. Escutelo com um par de cerdas basais, um par de apical; com cerca de cinco a seis cílios abaixo do nível das cerdas escutelares, próximo à margem látero-ventral. Prosterno nu. Duas cerdas proepisternais e duas proepimerais, as superiores maiores. Propleura nua. Espiráculo anterior vertical e alongado. Anepisterno com uma série de cinco cerdas na borda posterior. Catepisterno com pêlos de fundo longos e esparsos, 1:2 (a póstero-superior um pouco maior que a anterior porém menor que a pré-sutural). Anepímero com cílios na metade posterior. Catepímero nu. Espiráculo posterior horizontal, alongado, um pouco mais largo que 

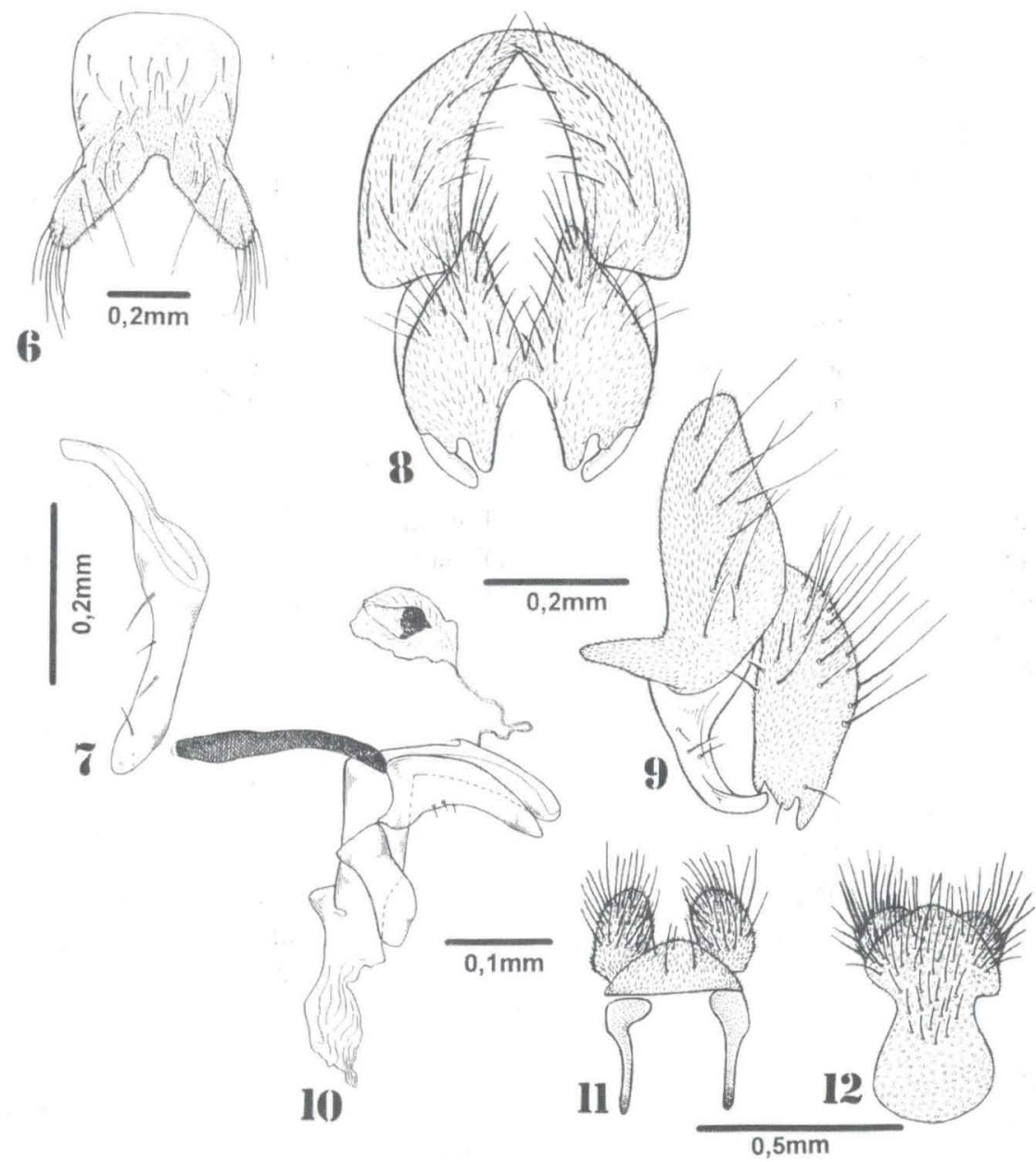

Figs 6-12. Paracyrtoneurina gluta. (6) Quinto esternito, vista dorsal; (7) surstilo direito, vista dorsal; (8) epândrio, placa cercal e surstilo, vista dorsal; (9) epândrio, placa cercal e surstilo, vista lateral; (10) complexo fálico, vista lateral; (11) ovipositor, vista dorsal; (12) ovipositor, vista dorsal.

o anterior e sem cílios negros na borda inferior. Caliptra inferior medindo 1,5-1,7 vezes a superior. Asa, $R_{1}$ e $R_{4+5}$, faces dorsal e ventral ciliadas; $M_{1+2}$ próximo ao ápice com uma discreta curvatura na direção da $\mathrm{R}_{4+5}$; dm-cu reta ou no máximo ligeiramente sinuosa; remígio, na face dorsal, nu. Fêmur I, nas faces anterior e ântero-ventral sem cerdas; faces póstero-ventral, posterior e póstero-dorsal com uma série de cerdas. Tíbia I, na face posterior com uma cerda no terço médio; nas faces dorsal, póstero-dorsal e póstero-ventral com uma cerda apical. Tarso com pêlos sensitivos longos, maiores na base do primeiro tarsômero. Fêmur II, faces posterior e póstero-dorsal com duas cerdas pré-apicais semelhantes entre si, fortes 
e inseridas obliquamente ao plano transversal do fềmur; face ventral com duas cerdas curtas e fortes. faces ântero-ventral, ventral e póstero-ventral com uma cerda apical. Tarso sem pêlos diferenciados na base do primeiro tarsômero. Fêmur III, na face ântero-ventral com duas cerdas no terço apical, face ântero-dorsal com uma série de cerdas; face posterior sem cerdas; face póstero-dorsal com uma cerda pré-apical. Tíbia III, nas faces ântero-ventral, ântero-dorsal e póstero-dorsal com uma ou duas, uma e uma cerda pequena no terço médio respectivamente; face ântero-dorsal com uma cerda pré-apical; face ventral com uma cerda apical. Tarso como no par médio.

Abdômen. Tergito I, na área voltada para o tórax, com uma faixa nua. Quinto esternito com reentrância central na margem posterior e incisão posterior profunda; superfície dorsal pouco angulosa (Fig. 6).

Terminália. Surstilo sem ciliação e com cerdas dispersas na margem interna (Fig. 7). Placa cercal com incisão posterior profunda (Figs 8-9). Parâmero com três curtas cerdas; gonópodo nu (Fig. 10).

Fêmea. Difere do macho nos seguintes caracteres: olhos separados por um espaço cerca de 2,4 vezes menor que a largura da cabeça no nível do ocelo anterior; facetas ântero-internas semelhantes às demais. Cerdas frontais em número de sete pares. Antena com cerca de 28 cílios. Fêmur II, na face ântero-ventral com dois pêlos longos no quarto basal; tíbia II, na face posterior com uma cerda no terço médio e uma sub-apical.

Terminália. Ovipositor pouco telescopável; epiprocto grande, triangular e ciliado e com cinco cerdas; tergitos estreitos (Figs 11-12).

Material examinado. Lectótipo e, uma fềmea 1108 [etiqueta bem pequena manuscrita]; Cyrtoneura/_gluta?/ Giglio-Tos [manuscrito]; Spilogaster_/ Tuxpango (Sumichr.). [Sumichrast] México.

Registro geográfico. México, Guatemala, Guiana, Costa Rica, Panamá e Venezuela.

AGRAdECIMENTOS. Ao Dr. Passerin d'Entrèves do "Museo ed Istituto di Zoologia Sistematica della Università de Torino", Itália, pela informação sobre depósito do material-tipo; ao Dr. Mauro Daccordi do "Museo Regionale di Scienze Naturali", Torino, Itália, pelo empréstimo de C. gluta; ao Dr. H. Schumann e Dr. H. Wendt, do "Museum für Naturkunde, Humboldt-Universität", Berlin, Alemanha, pelo empréstimo do síntipo macho de C. geminata; ao Sr. Luiz Antonio Alves da Costa, Museu Nacional, pela arte tinal das ilustrações.

\section{REFERÊNCIAS BIBLIOGRÁFICAS}

Carvalho, C.J.B. De; M.S. Couri; A.C. Pont; D. Pamplona \& S.M. Lopes. 1993. Parte II. Muscidae. In: C.J.B. DE Carvalho (Ed.). A Catalogue of the Fanniidae and Muscidae (Diptera) of the Neotropical Region. São Paulo, Sociedade Brasileira de Entomologia, $201 \mathrm{p}$.

Giglio-Tos, H. 1893. Diagnosi di nuovi generi e di nuove specie di Ditteri. VIII.

Boll. Musei Zool. Anat. comp. R. Univ. Torino 8 (147): 1-11. 
PAmplona, D. (no prelo). Nova Caracterização de Cyrtoneurina Giglio-Tos, 1893 e Descrição de Paracyrtoneurina gen. nov. e Apocyrtoneurina gen. nov. (Diptera, Muscidae, Cyrtoneurininae). Revta bras. Ent.

SNYDER, F.M. 1954. A Revision of Cyrtoneurina Giglio-Tos, with Notes on Related Genera (Diptera, Muscidae). Bull. Am. Mus. nat. Hist. 103: 417-464.

SteIn, P. 1904. Die Amerikanischen Anthomyiden des Königlichen Museums für

Naturkunde zu Berlin und des Ungarischen National Museums zu Budapest.

Annls hist.-nat. Mus. natn hung. 2: 414-495.

Recebido em 20.VI.1996; aceito em 25.VIII.1997. 